\title{
Research trends of microplastics in the soil environment: Comprehensive screening of effects
}

\author{
Shin Woong $\mathrm{Kim}^{1,2,3}{ }^{*}$, Matthias C. Rillig ${ }^{1,2}$ \\ 1 Institute of Biology, Freie Universität Berlin, 14195 Berlin, Germany \\ 2 Berlin-Brandenburg Institute of Advanced Biodiversity Research, 14195 Berlin, Germany \\ 3 Konkuk University, 120 Neungdong-ro, Gwangjin-gu, Seoul 05029, Korea
}

\section{H I G H L I G H T S}

- We collated and synthesized previous studies reporting on impacts of microplastics in soils.

- We found the most frequently used composition, shapes, size, and concentration.

- Species sensitivity distribution (SSD) method was used to screen the significant effects.

- We suggested special considerations are necessary to manage microplastics in soils.

\section{ARTICLE INFO}

Article history:

Received June 8, 2020

Revised December 30, 2020

Accepted January 9, 2021

\section{Keywords:}

Significant effect

Species sensitivity distribution

Soil

Soil properties
GRAPHICAL ABSTRACT

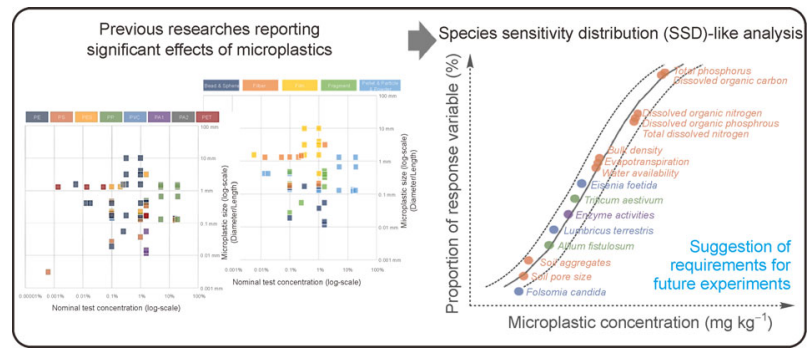

A B S T R A C T

We collated and synthesized previous studies that reported the impacts of microplastics on soil parameters. The data were classified and integrated to screen for the proportion of significant effects, then we suggest several directions to alleviate the current data limitation in future experiments. We compiled 106 datasets capturing significant effects, which were analyzed in detail. We found that polyethylene and pellets (or powders) were the most frequently used microplastic composition and shape for soil experiments. The significant effects mainly occurred in broad size ranges $(0.1-1 \mathrm{~mm})$ at test concentrations of $0.1 \%-10 \%$ based on soil dry weight. Polyvinyl chloride and film induced significant effects at lower concentrations compared to other compositions and shapes, respectively. We adopted a species sensitivity distribution (SSD) and soil property effect distribution (SPED) method using available data from soil biota, and for soil properties and enzymes deemed relevant for microplastic management. The predicted-no-effect-concentration (PNEC)-like values needed to protect $95 \%$ of soil biota and soil properties was estimated to be between 520 and $655 \mathrm{mg} \mathrm{kg}^{-1}$. This study was the first to screen microplastic levels with a view toward protecting the soil system. Our results should be regularly updated (e.g., quarterly) with additional data as they become available.

(c) The Author(s) 2021.

This article is published with open access at link.springer.com and journal.hep.com.cn

\section{Introduction}

The wide-spread use of plastic polymers has resulted in vast

* Corresponding author

E-mail address: swkim@zedat.fu-berlin.de (S.W. Kim) amounts of plastic litter being discarded or released into the environment (Andrady, 2011; Lambert and Wagner, 2018). These plastic polymers have slowly fragmented into smaller particles ( $<5 \mathrm{~mm}$ ), termed "microplastic" (Thompson et al., 2004; Law and Thompson, 2014). Microplastic pollution is a global environmental concern (PlasticsEurope, 2015). Previous studies have provided laboratory-scale evidence of both direct and indirect adverse effects of microplastic on marine 
and freshwater systems (Lambert and Wagner, 2018), while soil ecosystems have only recently become the focus of microplastic research (Rillig, 2012; Chae and An, 2018).

The abundance of microplastic in soils has reached a level that cannot be ignored (Horton et al., 2017; Bläsing and Amelung, 2018), and a growing body of evidence shows that microplastics causes changes in soils. Notably, soil invertebrates, including earthworms and springtails, can experience critical damage (e.g., mortality) following microplastic exposure (Huerta Lwanga et al., 2016; Ju et al., 2019), and can also suffer from constricted growth, reproduction, and behavior (Cao et al., 2017; Zhu et al., 2018a; Kim and An, 2019). Changes in microbial and enzyme activities have also been observed (Awet et al., 2018; Yang et al., 2018; Huang et al., 2019), as have impacts on agricultural crops from various microplastic compositions in soil (Qi et al., 2018; de Souza Machado et al., 2019). Although an increasing number of soil microplastic studies are becoming available, we still do not know which microplastic compositions, shapes, and concentrations are of particular concern for soils. Meanwhile, several convincing estimates of these parameters have been suggested for the aquatic environment (Backhaus and Wagner, 2018). There is initial evidence of composition-, size-, and shape-dependent effects of microplastic (de Souza Machado et al., 2018; Wan et al., 2019), and various soil parameters show different sensitivity to microplastic exposure. For example, soil physicochemical properties are altered with increasing microplastic concentrations (de Souza Machado et al., 2018), and these changes can trigger impacts on microbial biodiversity and enzyme activities (Liu et al., 2017; de Souza Machado et al., 2019). Several review papers have been published that succinctly summarize microplastics research. These have contributed to an improved scientific understanding of the topic (He et al., 2018; Hurley and Nizzetto, 2018; $\mathrm{Ng}$ et al., 2018; Xu et al., 2019). Recently, Bucci et al. (2019) conducted a systematic review and meta-analysis on microplastic effects, and determined the weight of evidence that various effects are dependent upon the size and concentration of the microplastic.

We now need a comprehensive, integrative assessment that can be used to evaluate potential microplastic management strategies, including the calculation of a guideline value. An ecological guideline value defines a measurable quantity of an indicator for a specific ecological community that is under considerable risk; guideline values are intended to help protect ecological systems. Governments and international agencies estimate these values for ecological risk assessment purposes (CCME, 2018; ECHA, 2008; NEPC, 2013; MOE, 2014). This strong methodology is based on probabilistic analysis of exposure data and toxicological responses, which can be used to suggest the predicted no-effect concentration (PNEC) as a guideline value (ECHA, 2008). The PNEC is estimated using the species sensitivity distribution (SSD) concept, which is a cumulative probability distribution of toxicity values for multiple species. Although a lack of available data and methodological limitations have led to uncertainty and a debate regarding which microplastic conditions lead to critical effects (Backhaus and Wagner, 2018), microplastics researchers need to consider possible management tools, including the SSD concept with welldocumented and transparent data.

In this study, we collated data from studies focused on the various physicochemical and biological effects of soil microplastics. We focused on microplastic effects with statistical support for the purpose of conducting an SSD-like analysis. We adopted this non-standard approach to capture the soilborne effects of microplastic, which behaves differently from other pollutants. This review explores the applicability of SSD to the soil environment, and offers guidance on how additional data should be collected to improve overall data quality.

\section{Methods}

\subsection{Data compilation and screening}

All published research used in this study were collected from online literature systems (Google scholar, ScienceDirect, and Wiley Online Library) using several key words: "soil plastic"; "soil microplastic"; and "microplastic" and the common names of each soil biota (i.e., plant, earthworm, springtail, etc.). The papers were published through November 30, 2019 and the database of microplastic reports should be regularly updated, perhaps quarterly. We found 82 scientific publications (Table S1), including perspectives, reviews, monitoring, effects on soil biota, and reports of changes in soil properties. We focused only on effects that were found to be statistically significant, which narrowed the publications down to 56 papers with effects on soil biota (microorganisms, enzymes, plants, and invertebrates) and soil properties. To achieve a robust summary, 20 papers focusing on non-soil media experiments were excluded, since no concentrations of microplasticsin the soil could be derived. In addition, 17 papers were ruled out because they had a purpose other than testing for effects; for example, they evaluated microplastic transport via soil biota, contamination-adsorption, and mixture toxicities compared to traditional pollutants. We also excluded one paper that focused on nano-sized plastic $(32.6 \mathrm{~nm})$, since the effects of nano-plastics are an independent issue. Thus, we selected a total of 18 papers for further study (Table S2).

The selected papers focused on nine different polymeric microplastic compositions: high-density polyethylene (HDPE); low-density polyethylene (LDPE); polyamide (PA); polyacrylic (PAN); polyethylene (PE); polyethylene terephthalate (PET); polyester (PES); polypropylene (PP); polystyrene (PS); polyvinyl chloride (PVC). The selected papers also focused on five shapes: bead (or sphere), fiber, film, fragment, and pellet (or particles/powder). Since each paper prepared the microplastics via different methods, microplastic sizes were defined with different units and ranges. We preferred using width or diameter, since length values were rarely given for fibers. When a paper provided a specific size range (e.g., 
$0.25-1 \mathrm{~mm}$ ), the median value (e.g., $0.625 \mathrm{~mm}$ ) was calculated for this review. When a size range was given as value smaller than a given size (e.g., $<0.3 \mathrm{~mm}$ ), we used half of this value (e.g., $0.15 \mathrm{~mm}$ ). This approach was adopted from substitution methods that allow for the extraction of available data from values below a detection limit (Lafleur et al., 2011). These unified values enabled us to visually describe research trends (see Fig. 1).

Papers differed in test duration ( $<1$ to 365 days) and test endpoints, including growth rate, enzyme activities, mortality, and gene expression. All selected papers provided statistical support $(p<0.05)$ of effects compared to the control. From these, we selected the lowest-observed-effect-concentration (LOEC) and the no-observed-effect-concentration (NOEC) at the longest duration. The LOEC is the lowest tested concentration that showed significant differences to the control group. The NOEC is the tested concentration below the LOEC. Since NOEC and LOEC were not specified in most papers, they were extracted from the test concentration ranges provided. When papers used a single concentration of microplastic, we used this concentration as the LOEC. Papers with no effects were excluded from this study. This estimation approach compensated for poor data availability, but more precise toxicity values should be used when available. We extracted a total of 106 data points from 18 publications (Table S2).

\subsection{Proportion of significant effects in the soil system}

We adopted an SSD-like method to screen the proportion of significant effects in soil. Chronic ecotoxicity data, such as NOEC and $10 \%$ effect concentration (EC10) were used as SSD input data to guarantee high reliability. Ecotoxicity data from various test species in different taxonomic groups were required; this data was converted and treated according to a standard guideline (ECHA, 2008; NEPC, 2013; MOE, 2014; CCME, 2018). In total, 56 of the 106 data points showed effects on the soil biota. First, we excluded 15 acute effects data (earthworm and springtail) according to the acute/chronic criterion of the standard guidelines (OECD, 1984; 2009). There were no acute data for plant or snail species (Table S2). Since non-traditional biotic endpoints are not recommended due to their low ecological relevance (CCME, 2018; ECHA, 2008; NEPC, 2013; MOE, 2014), only unambiguous biotic endpoints, such as survival, reproduction, and growth based on length, weight, and biomass were considered. Thus, 28 data points regarding cellular enzyme activities, gene expression, microbial diversity, and nutrient contents were excluded, leaving 13 remaining data points (Table S2). The chronic data from five species (Allium fistulosum, Eisenia fetida, Folsomia candida, Lumbricus terrestris, and Triticum aestivum) from three taxonomic groups (Entognatha, Monocotyledoneae, and Oligochaeta) were available, but these data were not sufficient to drive a standard SSD. According to guidelines, Australia requires at least 5-8 species from three taxonomic groups (NEPC, 2011), and ECHA recommends at least 10 NOEC values (preferably more than 15) from eight taxonomic groups (ECHA, 2008).

Microplastics are unique pollutants in environmental systems, especially in soil. They can affect soil physical structure and soil water dynamics (Liu et al., 2017; de Souza Machado et al., 2018; 2019). SSD analysis has never been used to assess these effects. Soil properties cannot be unilaterally quantified or defined, and they are not utilizable for standard SSD analysis; however, changes in soil properties that are caused by microplastics actually occur in soil media (Liu et al., 2017; de Souza Machado et al., 2019). Even if some studies report positive effects, such as decreases in bulk density, which is universally regarded as a good sign for crop cultivation, these effects are nevertheless undesirable as they represent deviations from the natural state. We found 50 data points of soil property and enzyme activity changes. A total of 16 acute data ( $\leqslant 2$ days) were excluded. A total of 47 data points, including soil biota (13) and soil properties (34), were classified (Table S2). This data set was used to screen the soil property effect distribution (SPED).

The NOEC values were directly used for SSD and SPED analysis (ECB, 2003; NEPC, 2013; MOE, 2014; CCME, 2018 ), while the LOEC values were divided by 2.5 to provide estimates of chronic NOEC data (ANZECC and ARMCANZ, 2000; Warne, 2001). This approach was adopted from a method developed by the Australian and New Zealand governments to derive water quality guideline values. In cases of insufficient chronic effects data, chronic LOEC values can be divided by 2.5 . The resulting estimated value should be annotated in the data sheets. Although this estimation has never been used for the soil environment, we used this methodology to compensate for the lack of available data (see Table S3-S5). We also suggest that these values should be replaced and updated when more data becomes available. The geometric mean values of the available data (raw or converted NOEC values) were independently calculated for soil biota (for SSD) and soil properties (for SPED), and were used as input data (Table S3). We used the USEPA SSD generator (ver. 1.0; USEPA, 2005), and estimated the PNEC-like values needed to protect soil biota (50\%) and soil properties (95\%). It also provides $95 \%$ prediction intervals and statistical parameters ( $\mathrm{R}^{2}$ and slope) for judging variability and quality of the data distribution.

\section{Results and discussion}

\subsection{Effects of microplastic in previous reports}

Broad and extensive responses to microplastic exposure have been reported. Each paper used statistical analysis as evidence of differences between microplastic treatments and control groups. Soil enzymatic activities, such as catalase (Huang et al., 2019), fluorescein diacetate hydrolysis (Liu et al., 2017; Huang et al., 2019; Liang et al., 2019), phosphatase (Yang et al., 2018), urease (Huang et al., 2019), and $\beta$ - 
glucosidase (Yang et al., 2018) were significantly increased by PP particles $(<180 \mu \mathrm{m}$ ) (Liu et al., 2017), PP powder $(<250 \mu \mathrm{m})$ (Yang et al., 2018), LDPE film (2 mm) (Huang et al., 2019), and PAN fiber (0.37-3.14 mm) (Liang et al., 2019). This increasing enzymatic activity trend may be highly linked to certain soil properties. Liu et al. (2017) reported that the addition of microplastics led to increased dissolved carbon, nitrogen, and phosphorus in soil. Furthermore, changes in soil structure and water dynamics may explain the impact microplastics have on plant or microbial activities (de Souza Machado et al., 2019).

Plant species studied in the selected papers included: Allium fistulosum (de Souza Machado et al., 2019), Lactuca sativa L. (Gao et al., 2019; Kim et al., 2019), Lepidium sativum L. (Bosker et al., 2019), Murraya exotica (Zhang et al., 2019a), Oryza sativa, Phaseolus radiates (Kim et al., 2019), Triticum aestivum (Judy et al., 2019; Qi et al., 2018), and Vicia faba (Jiang et al., 2019). In some papers, deionized water (Zhang et al., 2019a), emulsion solutions (Jiang et al., 2019), Hoagland solutions, and filter paper (Gao et al., 2019) were used instead of soil media. The research goals from Kim et al. (2019) and Judy et al. (2019) differed (e.g., contaminantadsorption and mixture toxicities). Thus, only two papers were available to extract data for the effect that microplastic in the soil has on plants. Qi et al. (2018) reported that micro-LDPE films $(0.25-1 \mathrm{~mm})$ significantly decreased root biomass for 61-139 days. The $2 \%$ concentration of PA beads $(15-20 \mu \mathrm{m})$ induced a reduction of various growth factors in $A$. fistulosum, while similar endpoints were significantly enhanced by PS fragments $(547-555 \mu \mathrm{m})$, PET $(222-258 \mu \mathrm{m})$ fragments, and PES fibers (5 mm) (de Souza Machado et al., 2019).

Earthworm species studied included: Lumbricus terrestris (Huerta Lwanga et al., 2016; Prendergast-Miller et al., 2019), Eisenia andrei (Rodríguez-Seijo et al., 2017), Eisenia fetida (Cao et al., 2017; Rodríguez-Seijo et al., 2018; Wang et al., 2019; Chen et al., 2020). Earthworm mortality was significantly increased by concentrations of $0.4 \%-1.2 \%$ of LDPE fragments $(<150 \mu \mathrm{m})$, while growth rates were decreased by the LDPE fragments (Huerta Lwanga et al., 2016) and by concentrations of $1 \%-2 \%$ PS spheres $(58 \mu \mathrm{m})$ (Cao et al., 2017). Histopathological damage, such as congestion, fibrosis, and inflammatory infiltrate, were also observed in earthworm intestinal systems after exposure to PE pellets (250-1000 um) (Rodríguez-Seijo et al., 2017). Cellular catalase activity was significantly decreased by LDPE pellets (250-1000 um) (Rodríguez-Seijo et al., 2018), while LDPE $(<400 \mu \mathrm{m}), \mathrm{PE}(<300 \mu \mathrm{m})$, and PS $(<250 \mu \mathrm{m})$ particles induced increasing trends (Wang et al., 2019; Chen et al., 2020). Glutathione S-transferase activity was significantly increased by $0.1 \%$ concentrations of LDPE pellets (250-1000 $\mu \mathrm{m}$; Rodríguez-Seijo et al., 2018), while exposure to PE particles $(<300 \mu \mathrm{m})$ resulted in reduced activity (Wang et al., 2019). The superoxide dismutase, peroxidase, and malondialdehyde activity was altered after acute exposure to PE $(<300 \mu \mathrm{m})$ and PS $(<250 \mu \mathrm{m})$ particles (Wang et al., 2019). These enzyme activities are highly related to defense mechanisms against oxidative stress by reactive oxygen species. Superoxide dismutase is the first line of defense, playing a role in the transformation of superoxide radicals to hydrogen peroxide (Mittler, 2002). Catalase and peroxidase are enzymes that reduce the harmful effects of hydrogen peroxide (Chao et al., 2016). Glutathione S-transferase activity is considered a major detoxification enzyme in the transformation of endogenous products during oxidative stress (Halliwell and Gutteridge, 1985). The contents of malondialdehyde were quantified to evaluate the lipid peroxidation in earthworms (Wang et al., 2019).

Folsomia candida (Zhu et al., 2018a; Ju et al., 2019) and Lobella sokamensis (Kim and An, 2019) were used in springtail bioassays. The growth and reproduction rates of $F$. candida were significantly decreased by PVC particles (80$250 \mu \mathrm{m})$ at $0.1 \%$ concentration, and by PE beads $(<500 \mu \mathrm{m})$ at $0.1 \%-1 \%$ concentration (Zhu et al., 2018a; Ju et al., 2019). Avoidance behavior and mortality increased in microplasticamended soil, including soil with PE beads $(<500 \mu \mathrm{m})$ (Ju et al., 2019). Kim and An (2019) evaluated the mobility of springtails in soil using image analysis and concluded that springtail mobility was significantly decreased by PS beads $(0.5 \mu \mathrm{m})$, PS fragments $(44,282$, and $676 \mu \mathrm{m})$, and PE beads (29 and $248 \mu \mathrm{m})$.

Caenorhabditis elegans, a free-living nematode, is generally known as a key species for use in toxicity assays, and in aquatic and soil testing methods as suggested by the American Society for Testing Materials (ASTM; ASTM, 2001), the International Organization for Standardization (ISO) (ISO, 2010), and by Williams and Dusenbery (1990). Previous studies using $C$. elegans conducted in a liquid test medium solution, and one study in soil are available with acute (24 h) exposure conditions (Kim et al., 2020). The enchytraeid, Enchytraeus crypticus, and the isopod, Porellio scaber, also responded to PE fragments $(183 \mu \mathrm{m})$, PE plates (1367 $\mu \mathrm{m})$, and PS beads $(0.05-0.1 \mu \mathrm{m})$. These experiments were not conducted in soil, but rather on E. crypticus medium and food sources (Kokalj et al., 2018; Zhu et al., 2018b).

Several pieces of evidence suggest that microplastic might cause changes in soil physicochemical properties. Bulk density, water holding capacity, hydraulic conductivity, and soil aggregation were affected by PES, PAN, and PE microplastic, with these microplastic-driven changes being highly dependent on microplastic composition (de Souza Machado et al., 2018). Dissolved organic carbon, total phosphorus, dissolved organic phosphorus, dissolved organic nitrogen, and total dissolved nitrogen were significantly altered by PP particles ( $<180 \mu \mathrm{m}$; Liu et al., 2017). Changes on soil structure and water dynamics occurred with PA bead $(15-20 \mu \mathrm{m})$, HDPE fragments $(643 \mu \mathrm{m})$, PP fragments $(647-$ $754 \mu \mathrm{m})$, PS fragments $(547-555 \mu \mathrm{m})$, PET fragments $(222$ $258 \mu \mathrm{m})$ and PES fibers ( $5 \mathrm{~mm}$; de Souza Machado et al., 2019). PE film $(2-10 \mathrm{~mm})$ and PES fibers $(<2.65 \mathrm{~mm})$ also induced changes in soil aggregation and pore size, which seemed to be directly linked to water evaporation and soil cracking (Wan et al., 2019; Zhang et al., 2019b). 


\subsection{Data summary of effects of microplastic in soil}

Specific microplastic sizes can cause significant effects at specific concentrations. This data is summarized in Fig. 1A, with the microplastic compositions represented in different colors. PE (including HDPE and LDPE) represented $39 \%$ of the total data, and was the most frequently used composition in the soil experiments. The effects seemed to mainly occur with particles of $0.1-1 \mathrm{~mm}$, and at test concentrations ranging from $0.1 \%-10 \%$. Microplastic of $1-10 \mathrm{~mm}$ in size, appears to increase the concentrations of significant effects in the order of PP, PE, PES, and PET. Fig. 1B depicts the same data as Fig. 1A, but focuses on microplastic shape (different colors). The shape proportions of fragments, beads (or spheres), films, fibers, and pellets (or particles/powder) were calculated as $15 \%, 18 \%, 20 \%, 23 \%$, and $25 \%$ of the total available 106
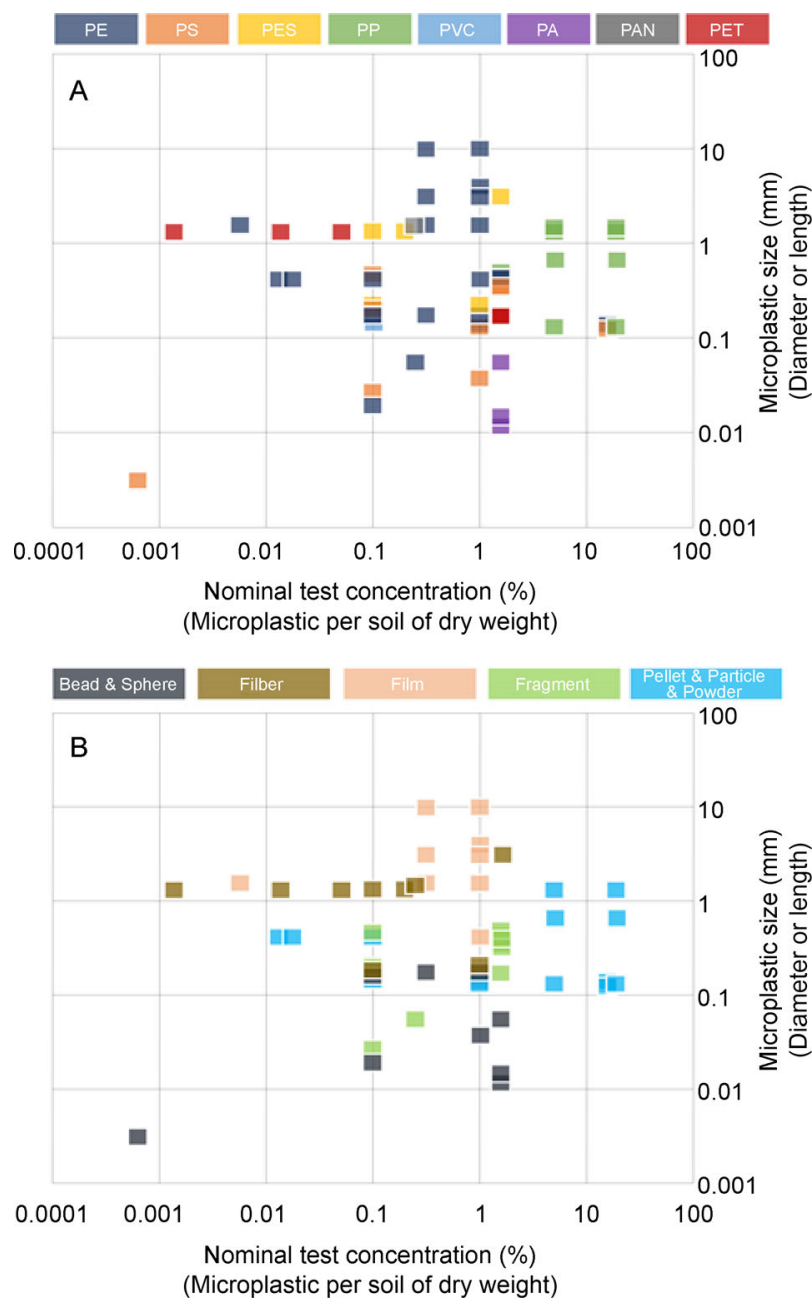

Fig. 1 Comprehensive screening of microplastic research. The figure represents previous data regarding the significant effects of specific sizes $(\mathrm{mm})$ of microplastics at specific concentrations (microplastic per soil dry weight). The data were classified by microplastic composition (A) and (B) shape. This figure is best viewed in color. data points (Table S2), respectively. The fiber and film shapes of microplastic were mainly large $(>1 \mathrm{~mm})$, while beads and sphere shapes were predominantly small.

\subsection{Proportion of significant effects in the soil system}

The available data regarding soil properties (23), microbial and enzyme activities (11), invertebrates (7), and plant species (6) were used as input data (Table S3), and can be presented in SSD and SPED analyses (Fig. 2). In order to evaluate the adequacy, a visual check of data curves is often used. Each data point in the SSD and SPED curve was located within the $95 \%$ prediction interval (Fig. 2). The slope, which determines how each factor is affected by the pollutants (Hagen and Douglas, 2014), was calculated as 2.687 and 1.225 for SSD and SPED curves, respectively. The coefficient of determination $\left(R^{2}\right)$ of the SSD and SPED curves were 0.941 and 0.943 , respectively, which suggested a good fit (Wheeler et al., 2002; Song et al., 2015). Soil properties, including dissolved organic carbon, total phosphorus, dissolved organic phosphorus, dissolved organic nitrogen, and total dissolved nitrogen, showed relatively low sensitivity to microplastic exposure (Liu et al., 2017), while soil aggregates and pore size exhibited high sensitivity (Zhang et al., 2019b). The effects on plants (Qi et al., 2018; de Souza Machado et al., 2019) and invertebrates (Chao et al., 2016; Huerta Lwanga et al., 2016) formed the intermediate range of the curve, but $F$. candida seemed to show a high sensitivity to microplastic exposure (Zhu et al., 2018a; Ju et al., 2019). Soil property data, especially soil aggregates and pore size, fell in line with data from soil biota (plants and earthworms). Since soil aggregate and pore size can influence many other parameters, including water dynamics, microbial activity, biodiversity, and nutrient cycles, we should keep in mind that effects could be broader than estimated by this data.

The PNEC-like values needed to protect soil biota and soil properties at $50 \%$ were estimated to be 2128 (SSD) and 14435 (SPED) $\mathrm{mg} \mathrm{kg}^{-1}$, while the values for $95 \%$ protection were 520 and $655 \mathrm{mg} \mathrm{kg}^{-1}$, respectively (Fig. 2). An abundance of microplastic has been reported in soils by several scientists, despite the limited data that is currently available. Microplastic can enter soil through multiple sources, including soil amendments, irrigation, and atmospheric input. Microplastics with various characteristics (composition, size, and shape) from different sources are also found in soil (Bläsing and Amelung, 2018). Fuller and Gautam (2016) reported that 300 to $67500 \mathrm{mg} \mathrm{kg}^{-1}$ of microplastic is found in industrial soils in Australia. Scheurer and Bigalke (2018) found $55.5 \mathrm{mg} \mathrm{kg}^{-1}$ in relatively pristine floodplain soils of Switzerland, while agricultural soils have been found to have 8 to 540 $\mathrm{mg} \mathrm{kg}^{-1}$ of microplastic (Zhang and Liu, 2018). According to our $95 \%$ protection concentration (520-655 mg kg-1), some agricultural and industrial areas would be expected to undergo significant changes caused by microplastic pollution. Although our estimate did not consider important microplastic characteristics, such as composition and shape, we believe 
that this approach reflects actual soil environment conditions since field sites typically contain a mixture of various microplastic shapes and compositions.

Using the same approach, we also analyzed microplastic composition and shape (Tables S4 and S5). As shown in Fig. 3A, PVC induces significant effects at very low concentrations. The sensitivity of the other plastic compositions was arrayed in the order LDPE, PES, PE, PA, PS, HDPE, PAN, and PP. PVC is generally regarded as the most hazardous microplastic (Lithner et al., 2011). Bisphenol A, which has been used as an additive in PVC products, is harmful to freshwater and marine organisms (Suhrhoff and Scholz-Böttcher, 2016; Zhang et al., 2017). PP also contains many additives, such as bumetrizole, to enhance its tolerance to oxidation, but the high toxicity of other derivatives has not been reported until now (Lahimer et al., 2017). For PP, high concentrations seemed to be required to detect any effects (Liu et al., 2017; Yang et al., 2018). Microplastic shape was arrayed in the order film, fiber, bead/sphere, fragment, and
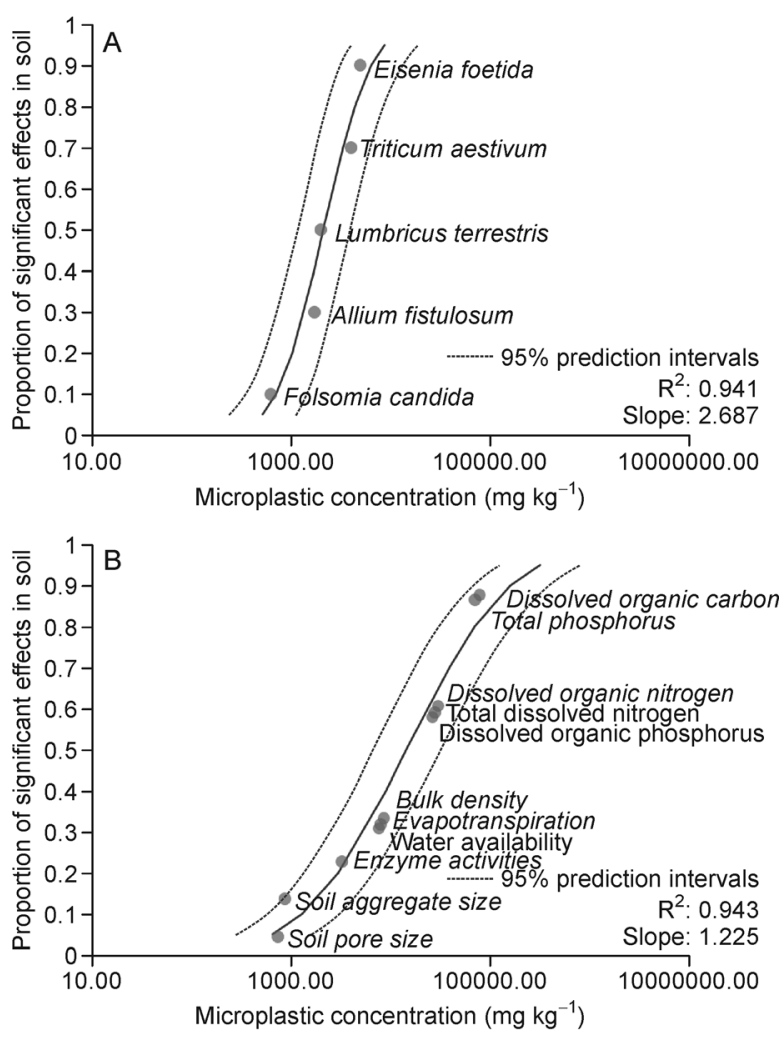

Fig. 2 Significant effect distribution of microplastics: (A) species sensitivity distribution (SSD) and (B) soil property effect distribution (SPED). Data on statistically significiant effects on soil biota and soil properties were collected, and lowest-observed-effect-concentration (LOEC) and noobserved-effect-concentration (NOEC) values were derived. The geometric mean values of the available data were calculated independently for each soil biota and soil property. An SSD generator was used to calculate the curve, and the coefficient of determination $\left(R^{2}\right)$, as well as the slope, and $95 \%$ prediction intervals. pellet/particles/powder on the curve (Fig. 3B). Film is the shape with the most pronounced effects. The given order may be due to the results of one paper, which reported a change in enzyme activities at a relatively low concentration ( $76 \mathrm{mg} \mathrm{kg}^{-1}$ ) of LDPE film (Huang et al., 2019). The importance of the fiber shape was highlighted in previous studies, which suggests the alteration of soil structures at low concentrations (de Souza Machado et al., 2018; 2019; Liang et al., 2019; Zhang et al., 2019b).

\subsection{Limitations and future directions}

In this study, previously reported significant microplastic effects were combined to predict the possible impact of microplastics at specific sizes and concentrations. Research trends were integrated into a figure that we feel will be helpful to decide the direction of future research. The PNEC-like
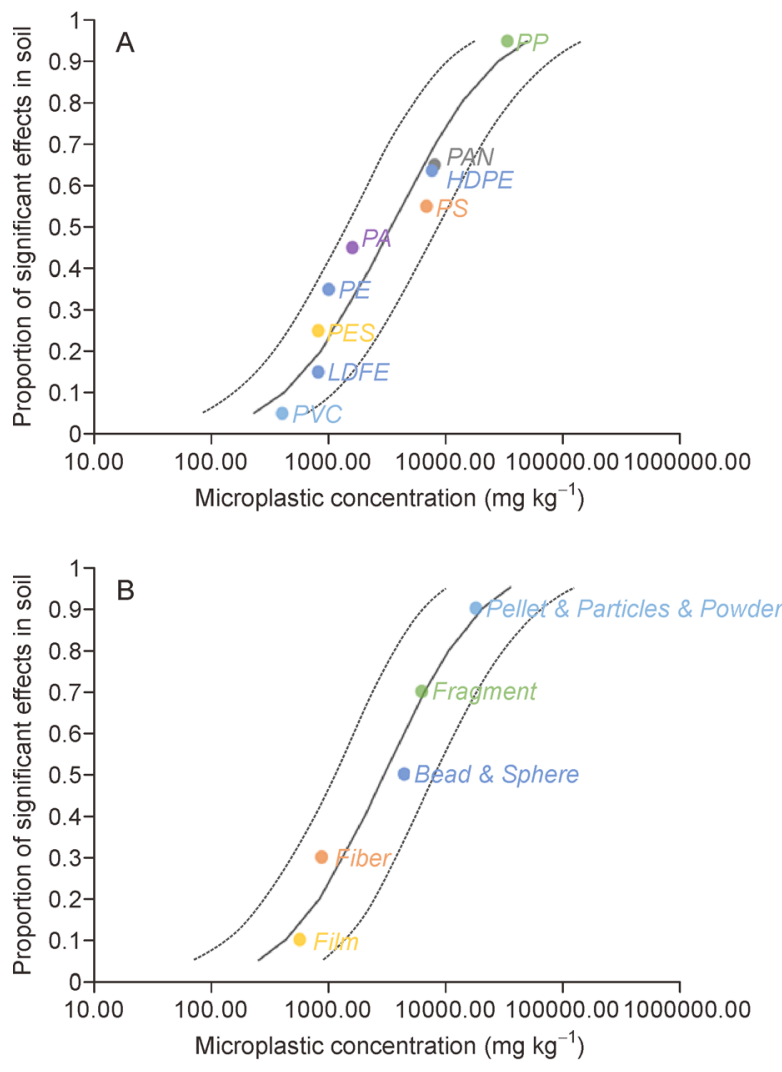

Fig. 3 Significant effect distribution depending on (A) composition and (B) shape of microplastic. Data on statistically supported effects were collected, and lowestobserved-effect-concentration (LOEC) and no-observedeffect-concentration (NOEC) values were derived. The geometric mean values were independently calculated for each microplastic type and shape, then a species sensitivity distribution (SSD) generator was used to calculate the curve. The related references for data in this figure are listed in Tables S4 (composition) and S5 (shape). 
values were derived using SSD and SPED curves, thus deriving a first estimate of a microplastic concentration level above which effects can be expected; however, these values are not final and cannot be used to inform policy. We established these values based on critical assumptions that have not previously been discussed in-depth, and there are some clear limitations. The most critical limitation is the lack of available data. The SSD-related guidelines recommend the use of NOEC or EC10 values for the appropriate doseresponse levels for available chronic data (ECHA, 2008; NEPC, 2013; MOE, 2014; CCME, 2018). Since many experiments have been conducted using a single microplastic concentration, NOEC or EC10 values could not be calculated due to a lack of information on dose-response relationships (Table S3). Hence, the single concentration was used as an LOEC value, and then converted into NOEC values according to guidelines. A formalized methodology with a reliability assessment is required to obtain data that are more useful for toxicological assessments, which can be directly linked with the reliability of SSD outcomes. Devising a standard methodology for testing microplastic effects should be considered an important future priority. All these points are sources of uncertainty, but should improve once additional data becomes available. To achieve this goal, future experiments should consider these issues. We also recommend that future experiments should be conducted in soil media to obtain microplastic concentration data for SSD analysis.

Since traditional SSD analysis requires high-quality input data for a single material, extensive toxicological data would be required to consider various microplastic characteristics. This may be nearly impossible to achieve in the immediate future, but it remains important to reflect on environmental realities in the meantime. Although data for each microplastic characteristic seemed to achieve acceptable SSD curves (Fig. 2), the size-, composition-, and shape-dependent effects should be verified to determine which factors can be integrated or weighted. As an example, we classified PVC composition and film shape as a more hazardous microplastic than others (Fig. 3). These characteristics should be considered in microplastic-specific guidance for future soil environmental management.

We decided to consider both increasing and decreasing effect trends, since they are both indicative of change in the soil system; the proportion of increasing trends was $57 \%$ of the total available data, with soil properties and enzyme activities representing $93 \%$ of these increasing trends (Table S2). Since microplastics have unique properties compared with more traditional pollutants, such as heavy metals, they can cause pronounced impacts on soil physical structure and water utilization functions (Liu et al., 2017; de Souza Machado et al., 2018; 2019; Wan et al., 2019; Zhang et al., 2019b). These soil changes may be highly linked to invertebrate responses, microorganisms, and even nutrient cycling (Liu et al., 2017; de Souza Machado et al., 2019). We observed several important facts and trends using our SSD and SPED curves. As shown in Fig. 2, soil aggregates and pore size, which are very important factors to determine soil properties and health, exhibited higher sensitivities than terrestrial plants or invertebrates. In addition, microplastic concentrationdependent effects on soil properties (e.g., bulk density, soil aggregates, and water evaporation rate) have been repeatedly reported (de Souza Machado et al., 2018; Wan et al., 2019). Even though we understand that soil properties and enzyme activities are not utilizable for standard SSD analysis (ECHA, 2008; NEPC, 2013; MOE, 2014; CCME, 2018), they should be considered for the special purpose of managing and estimating risks associated with microplastics, which also exert effects on physicochemical soil parameters.

\section{Conclusion}

Many previous studies have reported probable effects of microplastic in soil, which provide a scientific foundation for microplastic management. SSD-like analysis offers a formal approach for integrating such data. The suggested PNEC-like values in this study could be a management tool against microplastic pollution in soils, provided that these values are continuously updated. Future experiments should be conducted on soil media, and dose-response studies should be used to derive NOEC, LOEC, and EC10 values using the standard methodology. Such research would help improve the database presented here. In addition, further discussions are needed to decide whether soil properties and enzymes need to be included in microplastic pollution management strategies. This study is the first to estimate the microplastic levels required to protect and maintain soil environments.

\section{Acknowledgments}

This work was supported by a post-doctoral grant from the National Research Foundation of Korea funded by the Ministry of Science, ICT, and Future Planning (2019R1A6A3A03031386). MCR acknowledges support from an ERC Advanced Grant (grant no. 694368). Open Access funding enabled and organized by Projekt DEAL.

\section{Electronic supplementary material}

Supplementary material is available in the online version of this article at https://doi.org/10.1007/s42832-021-0077-3 and is accessible for authorized users.

\section{Open Access}

This article is licensed under a Creative Commons Attribution 4.0 International License, which permits use, sharing, adaptation, distribution and reproduction in any medium or format, as long as you give appropriate credit to the original author(s) and the source, provide a link to the Creative Commons licence, and indicate if changes were made. The images or other third party material in this article are included in the article's Creative 
Commons licence, unless indicated otherwise in a credit line to the material. If material is not included in the article's Creative Commons licence and your intended use is not permitted by statutory regulation or exceeds the permitted use, you will need to obtain permission directly from the copyright holder. To view a copy of this licence, visit http://creativecommons.org/licenses/by/ $4.0 \%$

\section{References}

American Society for Testing Materials (ASTM), 2001. Standard guide for conducting laboratory soil toxicity tests with the nematode Caenorhabditis elegans. E2172-01. ASTM International, West Conshohocken, PA, USA.

Andrady, A.L., 2011. Microplastics in the marine environment. Marine Pollution Bulletin 62, 1596-1605.

ANZECC and ARMCANZ, 2000. Australian and New Zealand Guidelines for Fresh and Marine Water Quality. The guidelines, Paper No. 4, Volume 1.

Awet, T.T., Kohl, Y., Meier, F., Straskraba, S., Grün, A.L., Ruf, T., Jost, C., Drexel, R., Tunc, E., Emmerling, C., 2018. Effects of polystyrene nanoparticles on the microbiota and functional diversity of enzymes in soil. Environmental Sciences Europe 30, 11.

Backhaus, T., Wagner, M., 2018. Microplastic in the environment: Much ado about nothing? A debate. Global Challenges. 190022.

Bläsing, M., Amelung, W., 2018. Plastics in soil: Analytical methods and possible sources. Science of the Total Environment 612, 422435.

Bosker, T., Bouwman, L.J., Brun, N.R., Behrens, P., Vijver, M.G., 2019. Microplastics accumulate on pores in seed capsule and delay germination and root growth of the terrestrial vascular plant Lepidium sativum. Chemosphere 226, 774-781.

Bucci, K., Tulio, M., Rochman, C.M., 2019. What is known and unknown about the effects of plastic pollution: A meta-analysis and systematic review. Ecological Applications. doi.org/10.1002/ eap. 2044

Canadian Council of Ministers of the Environment (CCME), 2018. http://st-ts.ccme.ca/en/index.html.

Cao, D., Wang, X., Luo, X., Liu, G., Zheng, H., 2017. Effects of polystyrene microplastics on the fitness of earthworms in an agricultural soil. IOP Conf. Earth Environmental Science 61, 012148.

Chae, Y., An, Y.J., 2018. Current research trends on plastic pollution and ecological impacts on the soil ecosystem: A review. Environmental Pollution 240, 387-395.

Chao, G., Jingbo, X., Ji, L., Zhengtao, L., 2016. Biological responses in the earthworm Eisenia fetida exposed to soils near a typical lead acid battery plant. Soil \& Sediment Contamination 25, 573-585.

Chen, Y., Liu, X., Leng, Y., Wang, J., 2020. Defense responses in earthworms (Eisenia fetida) exposed to low-density polyethylene microplastics in soils. Ecotoxicology and Environmental Safety 187, 109788.

de Souza Machado, A.A., Lau, C.W., Kloas, W., Bergmann, J., Bachelier, J.B., Faltin, E., Becker, R., Görlich, A.S., Rillig, M.C.,
2019. Microplastics can change soil properties and affect plant performance. Environmental Science \& Technology 53, 60446052.

de Souza Machado, A.A., Lau, C.W., Till, J., Kloas, W., Lehmann, A., Becker, R., Rillig, M.C., 2018. Impacts of microplastics on the soil biophysical environment. Environmental Science \& Technology 52, 9656-9665.

European Chemical Agency (ECHA), 2008. Guidance on Information Requirements and Chemical Safety Assessment. Finland, Helsinki.

Fuller, S., Gautam, A., 2016. A procedure for measuring microplastics using pressurized fluid extraction. Environmental Science \& Technology 50, 5774-5780.

Gao, M., Liu, Y., Song, Z., 2019. Effects of polyethylene microplastic on the phytotoxicity of di-n-butyl phthalate in lettuce (Lactuca sativa L. var. ramosa Hort). Chemosphere 237, 124482.

Halliwell, B., Gutteridge, J., 1985. Free Radicals in Biology and Medicine. Clarendon, Oxford, U.K.

He, D., Luo, Y., Lu, S., Liu, M., Song, Y., Lei, L., 2018. Microplastics in soils: Analytical methods, pollution characteristics and ecological risks. Trends in Analytical Chemistry 109, 163-172.

Hagen, T.G., Douglas, R.W., 2014. Comparative chemical sensitivity between marine Australian and Northern Hemisphere ecosystems: is an uncertainty factor warranted for water-quality-guideline setting? Environmental Toxicology and Chemistry 33, 1187-1192.

Horton, A.A., Walton, A., Spurgeon, D.J., Lahive, E., Svendsen, C., 2017. Microplastics in freshwater and terrestrial environments: Evaluating the current understanding to identify the knowledge gaps and future research priorities. Science of the Total Environment 586, 127-141.

Huang, Y., Zhao, Y., Wang, J., Zhang, M., Jia, W., Qin, X., 2019. LDPE microplastic films alter microbial community composition and enzymatic activities in soil. Environmental Pollution 254, 112983.

Huerta Lwanga, E., Gertsen, H., Gooren, H., Peters, P., Salánki, T., van der Ploeg, M., Besseling, E., Koelmans, A.A., Geissen, V., 2016. Microplastics in the terrestrial ecosystem: implications for Lumbricus terrestris (Oligochaeta, Lumbricidae). Environmental Science \& Technology 50, 2685-2691.

Hurley, R.R., Nizzetto, L., 2018. Fate and occurrence of micro(nano) plastics in soils: Knowledge gaps and possible risks. Current Opinion in Environmental Science \& Health 1, 6-11.

International Organization for Standardization (ISO), 2010. Water quality -Determination of the toxic effect of sediment and soil samples on growth, fertility and reproduction of Caenorhabditis elegans (Nematoda). ISO 10872:2010. Geneva, Switzerland.

Jiang, X., Chen, H., Liao, Y., Ye, Z., Li, M., Klobučar, G., 2019. Ecotoxicity and genotoxicity of polystyrene microplastics on higher plant Vicia faba. Environmental Pollution 250, 831-838.

Ju, H., Zhu, D., Qiao, M., 2019. Effects of polyethylene microplastics on the gut microbial community, reproduction and avoidance behaviors of the soil springtail, Folsomia candida. Environmental Pollution 247, 890-897.

Judy, J.D., Williams, M., Gregg, A., Oliver, D., Kumar, A., Kookana, R., Kirby, J.K., 2019. Microplastics in municipal mixed-waste organic outputs induce minimal short to long-term toxicity in key terrestrial biota. Environmental Pollution 252, 522-531. 
Kim, S.W., An, Y.J., 2019. Soil microplastics inhibit the movement of springtail species. Environment International 126, 699-706.

Kim, S.W., Kim, D., Chae, Y., Kim, D., An, Y.J., 2019. Crop-dependent changes in water absorption of expanded polystyrene in soil environments. Chemosphere 219, 345-350.

Kim, S.W., Kim, D., Jeong, S.W., An, Y.J., 2020. Size-dependent effects of polystyrene plastic particles on the nematode Caenorhabditis elegans as related to soil physicochemical properties. Environmental Pollution 258, 113740.

Kokalj, A. J., Horvat, P., Skalar, T., Kržan, A., 2018. Plastic bag and facial cleanser derived microplastic do not affect feeding behaviour and energy reserves of terrestrial isopods. Science of the Total Environment 615, 761-766.

Lafleur, B., Lee, W., Billhiemer, D., Lockhart, C., Liu, J., Merchant, N., 2011. Statistical methods for assays with limits of detection: Serum bile acid as a differentiator between patients with normal colons, adenomas, and colorectal cancer. Journal of Carcinogenesis 10 , 12.

Lahimer, M.C., Ayed, N., Horriche, J., Belgaied, S., 2017. Characterization of plastic packaging additives: Food contact, stability and toxicity. Arabian Journal of Chemistry 10, S1938-S1954.

Lambert, S., Wagner, M., 2018. Microplastics are Contaminants of Emerging Concern in Freshwater Environments: An Overview. In: Wagner, M., Lambert, S., eds. Freshwater Microplastics. Emerging Environmental Contaminants? Springer, Gewerbestrasse, Switzerland, pp. 1-23.

Lau, O.W., Wong, S.K., 2000. Contamination in food from packaging material. Journal of Chromatography. A 882, 255-270.

Law, K.L., Thompson, R.C., 2014. Oceans. Microplastics in the seas. Science 345, 144-145.

Liang, Y., Lehmann, A., Ballhausen, M.B., Muller, L., Rillig, M.C., 2019. Increasing temperature and microplastic fibers jointly influence soil aggregation by Saprobic Fungi. Frontiers in Microbiology 10, 2018.

Lithner, D., Larsson, A., Dave, G., 2011. Environmental and health hazard ranking and assessment of plastic polymers based on chemical composition. Science of the Total Environment 409, 3309-3324.

Liu, H., Yang, X., Liu, G., Liang, C., Xue, S., Chen, H., Ritsema, C.J., Geissen, V., 2017. Response of soil dissolved organic matter to microplastic addition in Chinese loess soil. Chemosphere 185, 907-917.

Liu, M., Lu, S., Song, Y., Lei, L., Hu, J., Lv, W., Zhou, W., Cao, C., Shi, H., Yang, X., He, D., 2018. Microplastic and mesoplastic pollution in farmland soils in suburbs of Shanghai, China. Environmental Pollution 242, 855-862.

Ministry of the Environment (MOE), 2014. Establishment of Ecological Risk Assessment Frame for Soil Pollution and its Application Scheme in Korea.

Mittler, R., 2002. Oxidative stress, antioxidants and stress tolerance. Trends in Plant Science 7, 405-410.

National Environment Protection Council (NEPC), 2013. Assessment Site Contamination schedule B5a: Guidelines on Ecological Risk Assessment.

Ng, E.L., Huerta Lwanga, E., Eldridge, S.M., Johnston, P., Hu, H.W., Geissen, V., Chen, D., 2018. An overview of microplastic and nanoplastic pollution in agroecosystems. Science of the Total Environment 627, 1377-1388.

Organization for Economic Cooperation and Development (OECD), 1984. OECD guidelines for the testing of chemicals No. 207. Earthworm acute toxicity tests.

Organization for Economic Cooperation and Development (OECD), 2009. OECD guidelines for the testing of chemicals No. 232. Collembolan reproduction test in soil.

PlasticsEurope, 2015. Plastics- the facts 2014/2015: An analysis of European plastics production, demand and waste data. PlasticsEurope, 1-34.

Prendergast-Miller, M.T., Katsiamides, A., Abbass, M., Sturzenbaum, S.R., Thorpe, K.L., Hodson, M.E., 2019. Polyester-derived microfibre impacts on the soil-dwelling earthworm Lumbricus terrestris. Environmental Pollution 251, 453-459.

Qi, Y., Yang, X., Pelaez, A.M., Huerta Lwanga, E., Beriot, N., Gertsen, H., Garbeva, P., Geissen, V., 2018. Macro- and micro- plastics in soil-plant system: Effects of plastic mulch film residues on wheat (Triticum aestivum) growth. Science of the Total Environment 645, 1048-1056.

Rillig, M.C., 2012. Microplastic in terrestrial ecosystems and the soil? Environmental Science \& Technology 46, 6453-6454.

Rodríguez-Seijo, A., da Costa, J.P., Rocha-Santos, T., Duarte, A.C., Pereira, R., 2018. Oxidative stress, energy metabolism and molecular responses of earthworms (Eisenia fetida) exposed to low-density polyethylene microplastics. Environmental Science and Pollution Research International 25, 33599-33610.

Rodríguez-Seijo, A., Lourenço, J., Rocha-Santos, T.A.P., da Costa, J., Duarte, A.C., Vala, H., Pereira, R., 2017. Histopathological and molecular effects of microplastics in Eisenia andrei Bouché. Environmental Pollution 220, 495-503.

Scheurer, M., Bigalke, M., 2018. Microplastics in Swiss floodplain soils. Environmental Science \& Technology 52, 3591-3598.

Song, W., Chen, S., Liu, J., Chen, J., Song, N., Li, N., Liu, B., 2015. Variation of $\mathrm{Cd}$ concentration in various rice cultivars and derivation of cadmium toxicity thresholds for paddy soil by species-sensitivity distribution. Journal of Integrative Agriculture $14,1845-1854$

Suhrhoff, T.J., Scholz-Böttcher, B.M., 2016. Qualitative impact of salinity, UV radiation and turbulence on leaching of organic plastic additives from four common plastics - A lab experiment. Marine Pollution Bulletin 102, 84-94.

Thompson, R.C., Olsen, Y., Mitchell, R.P., Davis, A., Rowland, S.J., John, A.W.G., McGonigle, D., Russell, A.E., 2004. Lost at sea: where is all the plastic? Science $304,838$.

USEPA. SSD generator (ver. 1.0). 2005.

Wan, Y., Wu, C., Xue, Q., Hui, X., 2019. Effects of plastic contamination on water evaporation and desiccation cracking in soil. Science of the Total Environment 654, 576-582.

Wang, J., Coffin, S., Sun, C., Schlenk, D., Gan, J., 2019. Negligible effects of microplastics on animal fitness and HOC bioaccumulation in earthworm Eisenia fetida in soil. Environmental Pollution 249, 776-784.

Warne, M.S.J., 2001. Derivation of the ANZECC and ARMCANZ water quality guidelines for toxicants. Australian Journal of Ecotoxicology 7, 123-136. 
Warne, M.S.J., King, O., Smith, R.A., 2018. Ecotoxicity thresholds for ametryn, diuron, hexazinone and simazine in fresh and marine waters. Environmental Science and Pollution Research International 25, 3151-3169.

Wheeler, J.R., Grist, E.P.M., Leung, K.M.Y., Morritt, D., Crane, M., 2002. Species sensitivity distributions: data and model choice. Marine Pollution Bulletin 45, 192-202.

Williams, P.L., Dusenbery, D.B., 1990. Aquatic toxicity testing using the nematode, Caenorhabditis elegans. Environmental Toxicology and Chemistry 9, 1285-1290.

Xu, B., Liu, F., Cryder, Z., Huang, D., Lu, Z., He, Y., Wang, H., Lu, Z., Brookes, P.C., Tang, C., Gan, J., Xu, J., 2019. Microplastics in the soil environment: Occurrence, risks, interactions and fate-A review. Critical Reviews in Environmental Science and Technology.

Yang, X., Bento, C.P.M., Chen, H., Zhang, H., Xue, S., Lwanga, E.H., Zomer, P., Ritsema, C.J., Geissen, V., 2018. Influence of microplastic addition on glyphosate decay and soil microbial activities in Chinese loess soil. Environmental Pollution 242, 338 347.

Zhang, C., Chen, X., Wang, J., Tan, L., 2017. Toxic effects of microplastic on marine microalgae Skeletonema costatum: Interactions between microplastic and algae. Environmental Pollution $220,1282-1288$.
Zhang, G.S., Liu, Y.F., 2018. The distribution of microplastics in soil aggregate fractions in southwestern China. Science of the Total Environment 642, 12-20.

Zhang, T.R., Wang, C.X., Dong, F.Q., Gao, Z.Y., Zhang, C.J., Zhang, X.J., Fu, L.M., Wang, Y., Zhang, J.P., 2019a. Uptake and translocation of styrene maleic anhydride nanoparticles in Murraya exotica plants as revealed by noninvasive, real-time optical bioimaging. Environmental Science \& Technology 53, 14711481.

Zhang, G.S., Zhang, F.X., Li, X.T., 2019b. Effects of polyester microfibers on soil physical properties: Perception from a field and a pot experiment. Science of the Total Environment 670, 1-7.

Zhou, Q., Zhang, H., Fu, C., Zhou, Y., Dai, Z., Li, Y., Tu, C., Luo, Y., 2018. The distribution and morphology of microplastics in coastal soils adjacent to the Bohai Sea and Yellow Sea. Geoderma 322, 201-208.

Zhu, D., Chen, Q.L., An, X.L., Yang, X.R., Christie, P., Ke, X., Wu, L.H., Zhu, Y.G., 2018a. Exposure of soil collembolans to microplastics perturbs their gut microbiota and alters their isotopic composition. Soil Biology \& Biochemistry 116, 302-310.

Zhu, B.K., Fang, Y.M., Zhu, D., Christie, P., Ke, X., Zhu, Y.G., $2018 \mathrm{~b}$. Exposure to nanoplastics disturbs the gut microbiome in the soil oligochaete Enchytraeus crypticus. Environmental Pollution 239, $408-415$. 